\title{
In defence of extrapolation but not improvisation in SARS-CoV-2 lung disease
}

Recently, the struggle against COVID-19 by respiratory and intensive care clinicians worldwide was punctuated by the sound of calls from a number of influential publications for an end to, as it were, improvisation and a return to principles of evidence-based medicine. The message was that management of SARS-CoV-2 lung disease needed to be guided strictly according to established dogma in acute respiratory distress syndrome unless supplanted by clinical trials specific to COVID-19. This position is predicated on the assumptions that knowledge about acute respiratory distress syndrome, and only about that entity, is directly translatable to SARS-CoV-2 lung disease, and that clinical trials enrolling COVID-19 patients will be completed in a sufficiently timely and rigorous fashion to influence empirical practice during the current pandemic. Clearly, there is room for an alternative perspective. In this Viewpoint, we aim to articulate a contrary point of view by resorting to arguments that are likely to resonate with frontline clinicians battling COVID-19.

At the height of the coronavirus disease 2019 (COVID-19) pandemic, a number of influential respiratory [1-3] and general medical publications [4] sounded a simultaneous call for restraint in, if one may speak for the authors, widespread clinical improvisation by the intensive care community managing lung disease associated with the severe acute respiratory syndrome coronavirus-2 (SARSCoV-2). Frontline clinicians have been advised to limit interventions to management strategies supported by existing randomised controlled trials (RCTs) in acute respiratory distress syndrome (ARDS) and withhold all other treatment aimed at the lung disease until results of RCTs specific to COVID-19 become available. For those in the trenches of the battle against COVID-19, this message contains both consonant and dissonant components. Many would agree with discouraging the use of dangerous therapies that have little or no precedent in the care of the patient with acute diffuse parenchymal lung disease (DPLD). One such example is the practice of systemic anticoagulation and even thrombolysis, born out of the observation that COVID-19 patients often have markedly elevated serum D-dimer levels [5] and some have thrombi in the pulmonary vasculature found at autopsy [6]. However, D-dimer is an unreliable marker of hypercoagulability in the setting of intense systemic inflammation that characterises severe COVID-19, and the presence of pulmonary vascular thrombosis is expected in patients who have succumbed to terminal diffuse alveolar damage (DAD) [7]. In contrast, the much-maligned corticosteroids have a long history in respiratory medicine for the treatment of immune cell-mediated acute DPLDs, a category to which SARS-CoV-2 lung disease is increasingly being shown to belong [8]. Several objections to the appeal for an end to improvisation are worth considering, one of which is that much of what is currently being implemented at the bedside may

@ERSpublications

It is debatable whether existing evidence-based principles for the management of acute respiratory distress syndrome are sufficiently applicable to \#SARSCoV2 lung disease to serve as strict dogma for the approach to this novel clinical entity https://bit.ly/2XjYPQs

Cite as: Epelbaum $\mathrm{O}$, Galperin I. In defence of extrapolation but not improvisation in SARS-CoV-2 lung disease. Breathe 2020; 16: 200113.

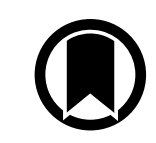

CrossMark

(c) ERS 2020 
not be improvisation at all but rather extrapolation. Notably, the approach being advocated by these authors [1-4] also qualifies as extrapolation.

\section{Improvisation versus extrapolation}

Pattern recognition has always been, and remains, a fundamental tool of the diagnostician and part of the "art of medicine." Entire medical disciplines, such as radiology and pathology, rest on this principle and function without the benefit of RCTs [9]. Just as radiologists and pathologists base decisions on pattern recognition, so could a pulmonologist when faced with a novel lung disease that resides in evidence-free territory: "To my experienced eye, previously unknown lung disease $X$ appears to share radiological and pathological features with known lung disease $Y$. Drug $Z$ has an established role in the treatment of lung disease $Y$; therefore, it is reasonable to hypothesise that drug $Z$ may also be beneficial in lung disease X." Near-universal corticosteroid administration for e-cigarette or vaping product use-associated lung injury is a recent example of this concept in a new lung disease devoid of RCT data [10]. Unlike the thought process behind anticoagulants and thrombolytics, application of therapies borrowed from analogous lung diseases is based on pattern recognition and would best be classified as extrapolation rather than improvisation, terms that carry very different connotations.

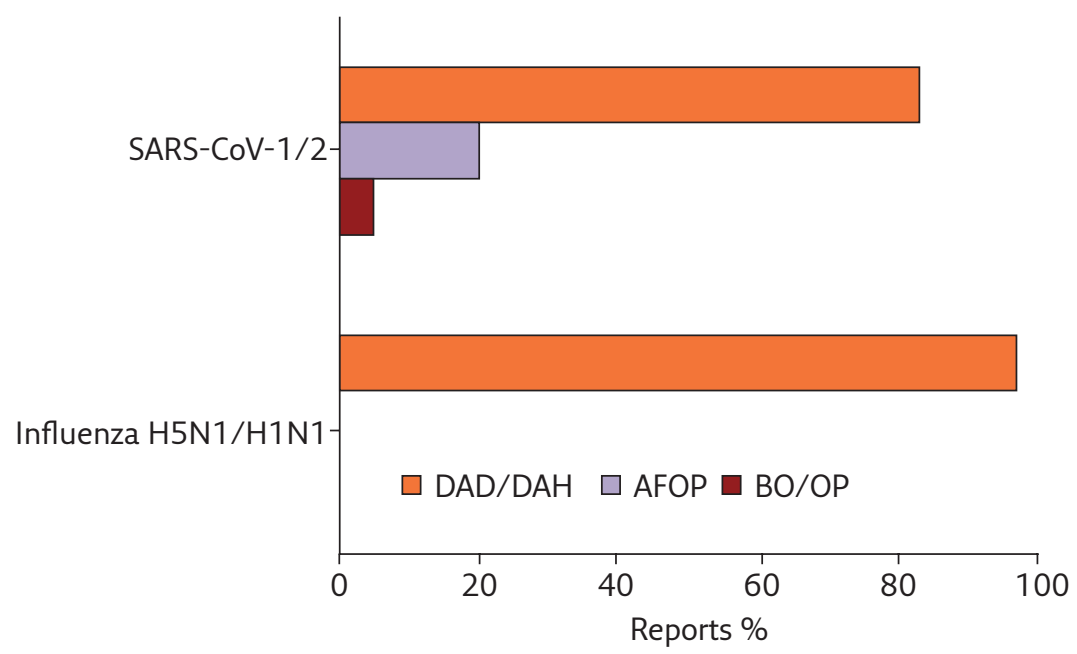

Figure 1 Comparison between the SARS Coronaviridae and recent pandemic influenza strains with respect to three histological patterns of lung involvement derived from the aggregation of major available English language reports. The characteristic influenza pattern of DAD and/ or bland diffuse alveolar haemorrhage (DAH) is nearly invariable across described cases, with bacterial pneumonia the principal finding in the remainder. All the influenza reports and all but a few of the Coronaviridae reports included in the calculation evaluated post mortem samples. Percentages for influenza H5N1 were derived from references tabulated in [18]. Percentages for influenza H1N1 were compiled from references [19-25]. SARS-CoV-1 percentages were derived from references tabulated in [26]. SARS-CoV-2 percentages were compiled from references [6, 17, 27-37]. BO: bronchiolitis obliterans.

\section{SARS-CoV-2 lung disease through the prism of ARDS histology}

ARDS is a diagnostic entity intended to correspond to the histological lesion of DAD, which is characterised by fulminant lung injury: disruption of the alveolar-capillary interface leading to alveolar filling by material normally confined by the endothelium. Because biopsy is rarely feasible, ARDS has been defined clinically and, therefore, has a number of mimics bearing non-DAD histology both with (acute eosinophilic pneumonia) and without (organising pneumonia (OP)) elements of lung injury [11]. Studies of patients fulfilling the Berlin definition of ARDS [12], the current standard, showed that fewer than half of cases subjected to biopsy [13] or autopsy [14] had DAD histologically; and on biopsy, $>20 \%$ were found to have OP, an acute DPLD associated with superior corticosteroid response and prognosis compared to DAD. OP and the related acute fibrinous and organising pneumonia (AFOP), which is likely to be immunologically triggered [15], have both been observed in post mortem samples obtained from patients with SARS-CoV-1 and SARS-CoV-2 lung disease $[16,17]$. The prevalence of these patterns would likely be even higher if ante mortem biopsies were available in significant numbers. Obscuration of earlier-stage histology by DAD can be expected in patients succumbing to terminal acute respiratory failure. The greater histological heterogeneity of lung involvement by the two Coronaviridae in comparison to influenza - the prototypical viral ARDS - is evident from examination of figure 1 , which illustrates the complete absence of OP and AFOP from any pathological reports describing lung findings in the latter. ARDS clinical trials attempt to identify and exclude patients with such prognostically favourable substrates [38], potentially limiting their applicability to COVID-19, and it cannot be argued that cases in which there is reason to suspect these substrates are ineligible for existing pharmacotherapeutic options.

\section{The problem of "lumping"}

Even if one were to accept the premise that SARSCoV-2 lung disease fits the phenotypic profile of ARDS, thoughtful observations suggest that it represents a peculiar endotype; that is, it has a unique pathobiology culminating in the common endpoint of ARDS. This empirical conclusion reached by many frontline intensivists explains the widespread departures from convention that have prompted the published admonitions. Implicitly, it echoes an important scientific perspective in contemporary ARDS research, namely that ARDS ought to be separated into distinct endotypes according to which therapy and patient should 
Table 1 Summary of major RCTs in ARDS that produced contradicting results

\begin{tabular}{|c|c|c|c|c|c|c|}
\hline Study parameter & Initial trial & Year & Result & Subsequent trial & Year & Result \\
\hline PP & Prone-Supine II [40] & 2009 & No impact on survival & PROSEVA [41] & 2013 & Improved survival \\
\hline OLV & LOVS [42] & 2008 & No impact on survival & ART [43] & 2017 & Reduced survival \\
\hline NMBA & ACURASYS [44] & 2010 & Improved survival & ROSE [45] & 2019 & No impact on survival \\
\hline CS & NHLBI [46] & 2006 & No impact on survival & DEXA-ARDS [38] & 2020 & Improved survival \\
\hline
\end{tabular}

be matched [39]. Urging clinicians to restrict management of a novel entity such as SARSCoV-2 lung disease to ARDS dogma can be viewed as sanctioning the older paradigm of "lumping" all ARDS rather than recognising the heterogeneity inherent in an imperfectly defined syndrome.

\section{Pessimism about help from clinical trials}

Reliance on completed ARDS RCTs to guide the management of SARS-CoV-2 lung disease is fraught with shortcomings. Glaring is the issue of external validity as, by definition, no clinical trial of ARDS prior to the COVID-19 pandemic enrolled a single patient with SARS-CoV-2. Moreover, the history of RCTs in ARDS is punctuated by inconsistency. There are numerous examples wherein an RCT appeared to answer a question only to be supplanted by a subsequent RCT that, due to differences in design, patient selection, timing and so on, produced contradicting results (table 1). This problem has plagued the field of
ARDS even outside the context of a pandemic; yet now, in the midst of one, the directive is to keep guns holstered until RCT signals arrive. Expecting RCTs conducted during a pandemic to be of sufficient quality to establish a durable standard of care is an optimistic proposition [47]. Results of RCTs hastily developed to address an immediate need in a worldwide emergency will be susceptible to scepticism. Should the results of such an RCT be concordant with a clinician's current philosophy, that practice will be reinforced; should they be discordant, the clinician will be able to point to the trial's methodological flaws as reason to continue the same approach.

The cautionary notes delivered in unison by thought leaders in the field of respiratory and intensive care medicine deserve the community's utmost attention. There is bound to be great variability in their acceptance, however, which will depend on their resonance with evolving bedside experience and eventual results of robust clinical trials. Currently, at the peak of the pandemic, extrapolation - not to be confused with improvisation - is largely all that is available to guide clinicians.

\section{Affiliations}

\section{Oleg Epelbaum ${ }^{1,2}$, Irene Galperin ${ }^{3,4}$}

${ }^{1}$ Division of Pulmonary, Critical Care, and Sleep Medicine, Westchester Medical Center, Valhalla, NY, USA. ${ }^{2}$ New York Medical College, Valhalla, NY, USA. ${ }^{3}$ Lenox Hill Hospital Northwell Health, New York, NY, USA. ${ }^{4}$ Donald and Barbara Zucker School of Medicine at Hofstra/Northwell, Hempstead, NY, USA.

\section{Conflict of interest}

None declared.

\section{References}

1. Waterer GW, Rello J, Wunderink RG. COVID-19: first do no harm. Am J Respir Crit Care Med 2020; 201: 1324-1325.

2. Singer BD, Jain M, Budinger GRS, et al. A call for rational intensive care in the era of COVID-19. Am J Respir Cell Mol Biol 2020; 63: 132-133.

3. Rice TW, Janz DR. In defense of evidence-based medicine for the treatment of COVID-19 ARDS. Ann Am Thorac Soc 2020; 17: 787-789.

4. Zagury-Orly I, Schwartzstein RM. Covid-19 - a reminder to reason. N EnglJ Med 2020; 383: e12.
5. Connors JM, Levy JH. COVID-19 and its implications for thrombosis and anticoagulation. Blood 2020; 13 : 2033-2040.

6. Wichmann D, Sperhake JP, Lütgehetmann M, et al. Autopsy findings and venous thromboembolism in patients with COVID-19: a prospective cohort study. Ann Intern Med 2020; 173: 268-277.

7. Tomashefski JF Jr, Davies P, Boggis C, et al. The pulmonary vascular lesions of the adult respiratory distress syndrome. Am J Pathol 1983; 112: 112-126. 
8. Zhang Y, Gao Y, Qiao L, et al. Inflammatory response cells during acute respiratory distress syndrome in patients with coronavirus disease 2019 (COVID-19). Ann Intern Med 2020: 173: 402-404.

9. Jha S, Topol EJ. Adapting to artificial intelligence: radiologists and pathologists as information specialists. JAMA 2016; 316: 2353-2354

10. Layden JE, Ghinai I, Pray I, et al. Pulmonary illness related to e-cigarette use in Illinois and Wisconsin - final report. N EnglJ Med 2020; 382: 903-916.

11. Schwarz MI, Albert RK. "Imitators" of the ARDS: implications for diagnosis and treatment. Chest 2004; 125: 1530-1535.

12. ARDS Definition Task Force, Ranieri VM, Rubenfeld GD et al. Acute respiratory distress syndrome: the Berlin Definition. JAMA 2012; 307: 2526-2533.

13. Gerard L, Bidoul T, Castanares-Zapatero D, et al. Open lung biopsy in nonresolving acute respiratory distress syndrome commonly identifies corticosteroid-sensitive pathologies, associated with better outcome. Crit Care Med 2018; 46: 907-914

14. Thille AW, Esteban A, Fernández-Segoviano $\mathrm{P}$, et al Comparison of the Berlin definition for acute respiratory distress syndrome with autopsy. Am J Respir Crit Care Med 2013; 187: 761-767.

15. Pedersen SF, Ho YC. SARS-CoV-2: a storm is raging. Clin Invest 2020; 130: 2202-2205.

16. Ng WF, To KF, Lam WW, et al. The comparative pathology of severe acute respiratory syndrome and avian influenza A subtype H5N1 - a review. Hum Pathol 2006; 37: 381-390

17. Copin MC, Parmentier E, Duburcq T, et al. Time to consider histologic pattern of lung injury to treat critically ill patients with COVID-19 infection. Intensive Care Med 2020; 46: 1124-1126.

18. Korteweg C, Gu J. Pathology, molecular biology, and pathogenesis of avian influenza $A(H 5 N 1)$ infection in humans. Am J Pathol 2008; 172: 1155-1170.

19. Gill JR, Sheng ZM, Ely SF, et al. Pulmonary pathologic findings of fatal 2009 pandemic influenza A/H1N1 viral infections. Arch Pathol Lab Med 2010; 134: 235-243.

20. Mauad T, Hajjar LA, Callegari GD, et al. Lung pathology in fatal novel human influenza $\mathrm{A}(\mathrm{H} 1 \mathrm{~N} 1)$ infection. Am J Respir Crit Care Med 2010; 181: 72-79.

21. Harms PW, Schmidt LA, Smith LB, et al. Autopsy findings in eight patients with fatal $\mathrm{H} 1 \mathrm{~N} 1$ influenza. Am Clin Pathol 2010; 134: 27-35.

22. Rosen DG, Lopez AE, Anzalone ML, et al. Postmortem findings in eight cases of influenza A/H1N1. Mod Pathol 2010; 23: 1449-1457

23. Bal A, Suri V, Mishra B, et al. Pathology and virology findings in cases of fatal influenza $\mathrm{A} \mathrm{H} 1 \mathrm{~N} 1$ virus infection in 2009-2010. Histopathology 2012; 60: 326-335.

24. Nakajima N, Sato Y, Katano H, et al. Histopathological and immunohistochemical findings of 20 autopsy cases with 2009 H1N1 virus infection. Mod Pathol 2012; 25: 1-13.

25. Shelke VN, Kolhapure RM, Kadam D, et al. Pathologic study of pandemic influenza A (H1N1) 2009 cases from India. Pathol Int 2012; 62: 36-42.

26. Gu J, Korteweg C. Pathology and pathogenesis of severe acute respiratory syndrome. Am J Pathol 2007; 170: 1136-1147.

27. Menter T, Haslbauer JD, Nienhold R, et al. Post-mortem examination of COVID19 patients reveals diffuse alveolar damage with severe capillary congestion and variegated findings of lungs and other organs suggesting vascular dysfunction. Histopathology 2020; in press [https://doi. org/10.1111/his.14134].

28. Lax SF, Skok K, Zechner P, et al. Pulmonary arteria thrombosis in COVID-19 with fatal outcome: results from a prospective, single-center, clinicopathologic case series. Ann Intern Med 2020; 173: 350-361.
29. Magro C, Mulvey JJ, Berlin D, et al. Complement associated microvascular injury and thrombosis in the pathogenesis of severe COVID-19 infection: a report of five cases. Trans/ Res 2020; 220: 1-13.

30. Fox SE, Akmatbekov A, Harbert JL, et al. Pulmonary and cardiac pathology in Covid-19: the first autopsy series from New Orleans. medRxiv 2020; pre-print [https://doi.org /10.1101/2020.04.06.20050575]

31. Barton LM, Duval EJ, Stroberg E, et al. COVID-19 autopsies, Oklahoma, USA. Am J Clin Pathol 2020; 153: 725-733.

32. Tian S, Hu W, Niu L, et al. Pulmonary pathology of early-phase 2019 novel coronavirus (COVID-19) pneumonia in two patients with lung cancer. J Thorac Oncol 2020; 15 : 700-704.

33. Zeng Z, Xu L, Xie XY, et al. Pulmonary pathology of early phase COVID-19 pneumonia in a patient with a benign lung lesion. Histopathology 2020; in press [https://doi. org/10.1111/his.14138]

34. Konopka KE, Wilson A, Myers JL. Postmortem lung findings in a patient with asthma and coronavirus disease 2019. Chest 2020; 158: e99-e101.

35. Pernazza A, Mancini M, Rullo E, et al. Early histologic findings of pulmonary SARS-CoV-2 infection detected in a surgical specimen. Virchows Arch 2020; in press [https://doi. org/10.1007/s00428-020-02829-1].

36. Xu Z, Shi L, Wang Y, et al. Pathological findings of COVID-19 associated with acute respiratory distress syndrome. Lancet Respir Med 2020; 8: 420-422.

37. Zhang $\mathrm{H}$, Zhou $\mathrm{P}$, Wei $\mathrm{Y}$, et al. Histopathologic changes and SARS-CoV-2 immunostaining in the lung of a patient with COVID-19. Ann Intern Med 2020; 172: 629-632.

38. Villar J, Ferrando C, Martínez D, et al. Dexamethasone treatment for the acute respiratory distress syndrome: a multicentre, randomised controlled trial. Lancet Respir Med 2020; 8: 267-276.

39. Prescott HC, Calfee CS, Thompson BT, et al. Toward smarter lumping and smarter splitting: rethinking strategies for sepsis and acute respiratory distress syndrome clinical trial design. Am J Respir Crit Care Med 2016; 194: 147-155.

40. Taccone P, Pesenti A, Latini R, et al. Prone positioning in patients with moderate and severe acute respiratory distress syndrome: a randomized controlled trial. JAMA 2009; 302: 1977-1984.

41. Guérin C, Reignier J, Richard JC, et al. Prone positioning in severe acute respiratory distress syndrome. $N$ Engl J Med 2013; 368: 2159-2168.

42. Meade MO, Cook DJ, Guyatt GH, et al. Ventilation strategy using low tidal volumes, recruitment maneuvers, and high positive end-expiratory pressure for acute lung injury and acute respiratory distress syndrome: a randomized controlled trial. JAMA 2008; 299: 637-645.

43. Writing Group for the Alveolar Recruitment for Acute Respiratory Distress Syndrome Trial (ART) Investigators, Cavalcanti AB, Suzumura ÉA, et al. Effect of lung recruitment and titrated positive end-expiratory pressure (PEEP) vs low peep on mortality in patients with acute respiratory distress syndrome: a randomized clinical trial. JAMA 2017; 318: 1335-1345.

44. Papazian L, Forel JM, Gacouin A, et al. Neuromuscular blockers in early acute respiratory distress syndrome. N EnglJ Med 2010; 363: 1107-1116.

45. National Heart, Lung, and Blood Institute PETAL Clinical Trials Network, Moss M, Huang DT, et al. Early neuromuscular blockade in the acute respiratory distress syndrome. N Engl J Med 2019; 380: 1997-2008.

46. Steinberg KP, Hudson LD, Goodman RB, et al. Efficacy and safety of corticosteroids for persistent acute respiratory distress syndrome. N Engl J Med 2006; 354: 1671-1684.

47. Angus DC. Optimizing the trade-off between learning and doing in a pandemic. JAMA 2020; 323: 1895. 